\title{
Efforts toward rapid construction of the cortistatin A carbocyclic core via enyne-ene metathesis $\uparrow$
}

\author{
Corinne Baumgartner, Sandy Ma, Qi Liu and Brian M. Stoltz*
}

Received 17th March 2010, Accepted 4th May 2010

First published as an Advance Article on the web 24th May 2010

DOI: 10.1039/c004275g

Our efforts toward the construction of the carbocylic core of cortistatin A via an enyne-ene metathesis are disclosed. Interestingly, an attempted $\mathrm{S}_{\mathrm{N}} 2$ inversion of a secondary mesylate in our five-membered D-ring piece gave a product with retention of stereochemistry.

The discovery of novel anti-angiogenic agents has become an active area of drug therapy research given their therapeutic applications in the treatment of cancer, autoimmune diseases, macular degeneration, as well as other diseases. ${ }^{1}$ A series of unique abeo-9(10,19)-androstane-type steroidal alkaloids were isolated from the marine sponge Corticium simplex in 2006 and 2007, ${ }^{2}$ some of which possessed significant anti-angiogenic activity. The most potent member, cortistatin A (1) demonstrated highly selective growth inhibition of human umbilical vein endothelial cells $\left(\mathrm{IC}_{50}=1.88 \mathrm{nM}\right.$, selectivity index $\left.>3000\right)$ with relatively no general toxicity toward other cell types. The biological activity, as well as the intriguing molecular structure of $\mathbf{1}$, have led to several total syntheses ${ }^{3}$ and efforts toward the construction of the cortistatin A core. ${ }^{4}$

In our approach to the synthesis of cortistatin A (1), we envisioned that the $[6,7,6,5]$ core could arise via an intramolecular tandem enyne-ene metathesis (Scheme 1). ${ }^{5}$ To examine the feasibility of such a step, we focused on the synthesis of alkynyl

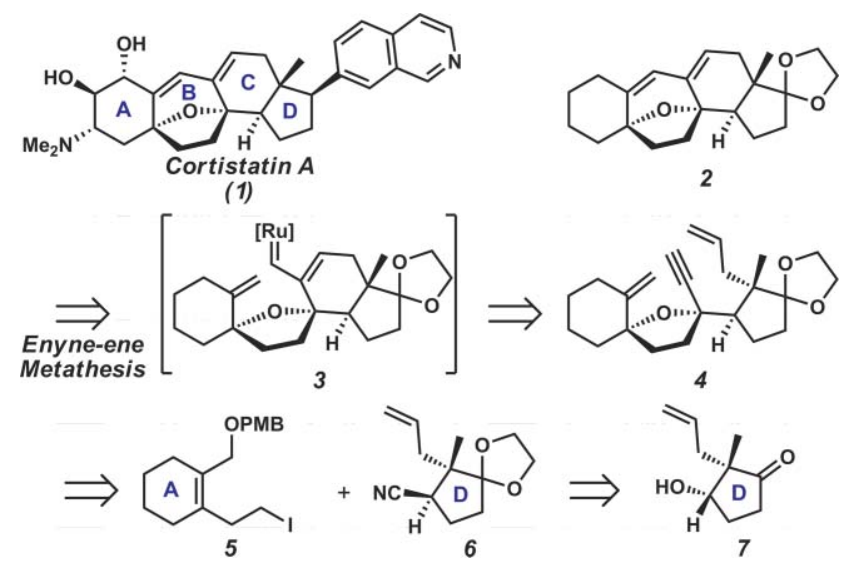

Scheme 1

The Arnold and Mabel Beckman Laboratories of Chemical Synthesis, Division of Chemistry and Chemical Engineering, California Institute of Technology, 1200 E. California Boulevard, MC 164-30, Pasadena, CA 91125, USA. E-mail: stoltz@caltech.edu; Fax: +1 626564 9297; Tel: +1 6263956064

$\dagger$ Electronic supplementary information (ESI) available: General experimental procedures, characterization data, NMR, and IR spectra. See DOI: $10.1039 / \mathrm{c} 004275 \mathrm{~g}$ diene $\mathbf{4}$ as a model precursor for the key enyne-ene metathesis to give pentacyclic model diene $\mathbf{2}$. Alkynyl diene $\mathbf{4}$ could arise from alkyl iodide $\mathbf{5}$ and nitrile $\mathbf{6}$. Nitrile $\mathbf{6}$, in turn, could be derived from ketone 7, which has been synthesized in enantiopure form, ${ }^{6}$ thus providing a direct route for an asymmetric synthesis of the cortistatin A carbocyclic core.

Our synthesis of the A-ring portion of cortistatin A commenced from cyclohexanone $\mathbf{8}$, which was converted to the allylic alcohol 9 through treatment with $\mathrm{PBr}_{3}$ and DMF followed by a DIBAL reduction of the resulting aldehyde (Scheme 2$).{ }^{7} \mathrm{PMB}$ protection of the allylic alcohol yielded ether 10, which was coupled to vinyltributylstannane to afford diene 11. Hydroboration of diene 11 and subsequent exposure of the resultant primary alcohol to triphenylphosphine and iodine produced iodide 5 .

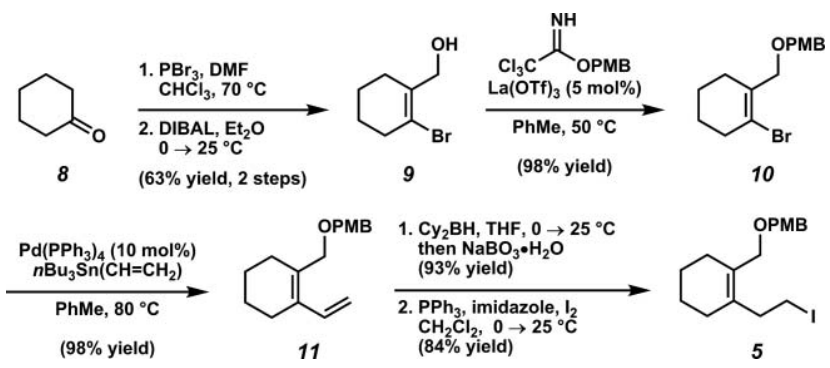

Scheme 2

With the A-ring precursor 5 in hand, we set out to make the D-ring portion in an asymmetric manner (Scheme 3). Treatment of dione 12 with baker's yeast provided a 9:1 mixture of chromatographically separable alcohols 7 and $\mathbf{1 3} .{ }^{5}$ We envisioned that subjecting the major product alcohol $7^{8}$ to $\mathrm{S}_{\mathrm{N}} 2$ displacement conditions would install the final carbon of the D-ring moiety and set the desired absolute and relative stereochemistry. However, mesylation of alcohol 7 followed by treatment with potassium cyanide in DMSO surprisingly afforded nitrile 15, a product with net retention of stereochemistry at $\mathrm{C}(14)$. This unexpected result was confirmed via NOESY correlations of alcohols 7 and 13 and nitrile 15, and by X-ray diffractometry of crystalline compounds derived from alcohol 7 and nitrile 15. ${ }^{9}$ A possible explanation for this unexpected outcome is that the mechanism proceeds via oxetane 16, which is postulated to arise from reversible cyanohydrin formation of mesylate 14. Ring cleavage by nucleophilic attack of cyanide at $\mathrm{C}(14)$ of oxetane $\mathbf{1 6}$ would ultimately afford nitrile $\mathbf{1 5 .}$

Despite this unusual result we wished to continue the synthesis of the model system due to our interest in testing the enyne-ene metathesis. To advance ketone $\mathbf{1 5}$, we protected the ketone as the acetal to give $\mathbf{1 7}$. Nitrile $\mathbf{1 7}$ was then reduced to the aldehyde 


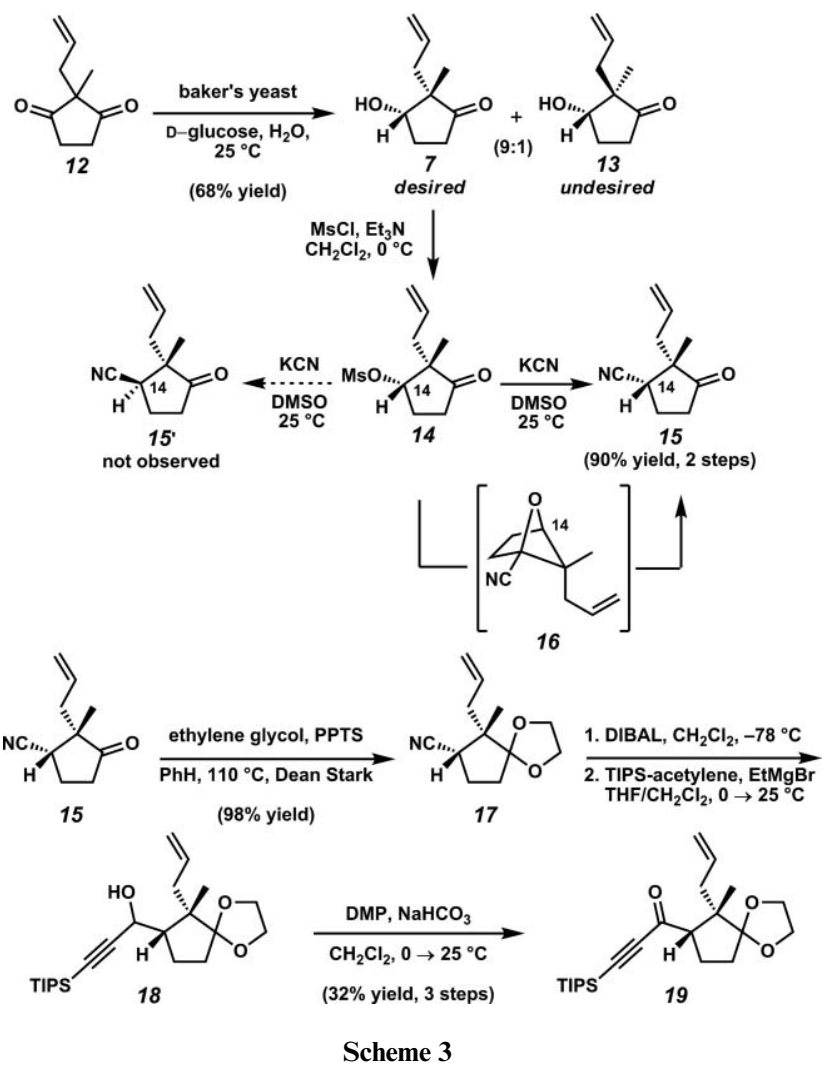

and after treatment with TIPS-acetylene and $\mathrm{EtMgBr}$, afforded alcohol 18 as a mixture of diastereomers. Alcohol 18 was oxidized with Dess-Martin periodinane (DMP) to give ketone 19.

With our A-ring (5) and epi-D-ring (19) precursors in hand, we then coupled the two together by treating vinyl iodide 5 with $t$-BuLi and adding the resultant lithio species to ketone 19 (Scheme 4).
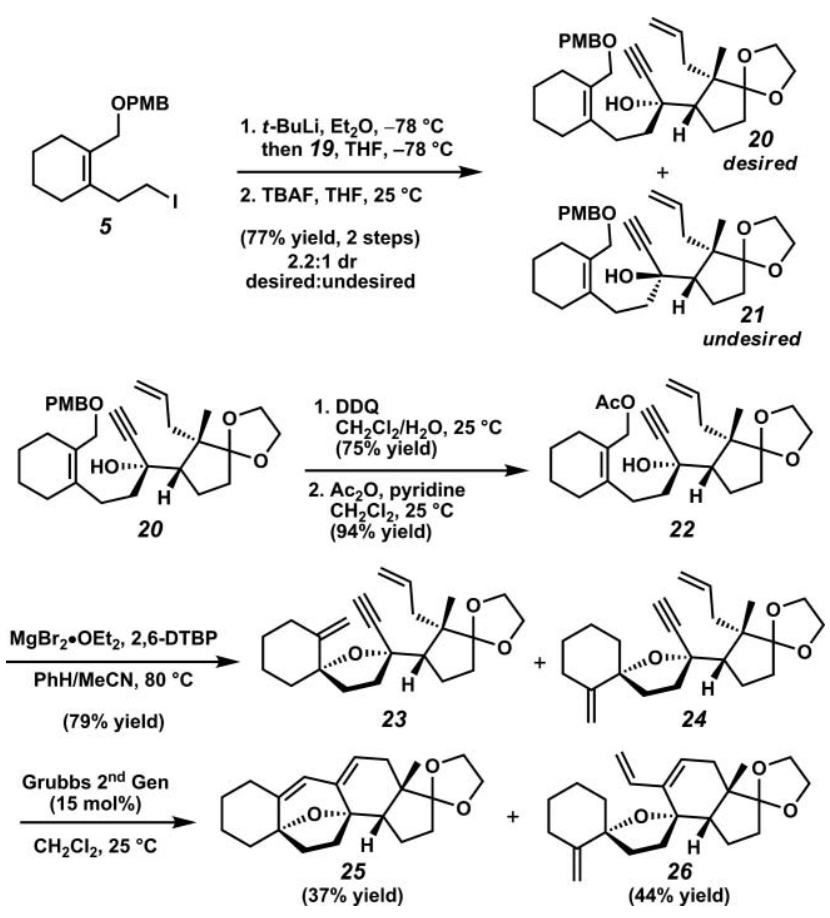

Scheme 4
Subsequent TIPS cleavage with TBAF gave a 2.2:1 mixture of the desired alcohol 20 (Felkin-Anh product) and the undesired alcohol 21. After separation by column chromatography, $\mathrm{PMB}$ ether $\mathbf{2 0}$ was converted to allylic acetate $\mathbf{2 2}$. Treatment of $\mathbf{2 2}$ with $\mathrm{MgBr}_{2}$ gave a 1:1 mixture of substituted tetrahydrofurans $\mathbf{2 3}$ and $\mathbf{2 4},{ }^{10}$ which were inseparable by column chromatography. Nonetheless, subjection of the mixture of $\mathbf{2 3}$ and $\mathbf{2 4}$ to Grubbs secondgeneration catalyst produced the desired enyne-ene metathesis $[6,7,6,5]$-core $\mathbf{2 5}$ in $37 \%$ yield and the enyne metathesis product 26 in $44 \%$ yield.

We planned to establish the absolute and relative stereochemistry of our metathesis products via derivatization to give compounds suitable for X-ray crystallography analysis. Attempts to convert the [6,7,6,5]-core $\mathbf{2 5}$ or the enyne product $\mathbf{2 6}$ to crystalline compounds were not successful. However, we were able to derivatize the undesired alcohol $\mathbf{2 1}$ by proceeding through a similar route as outlined in Scheme 4 for $\mathbf{2 0}$ to ultimately afford enyne product 27. Enyne product $\mathbf{2 7}$ was then transformed to oxime 28, which was acylated with $p$-bromobenzoylchloride to furnish 29, a compound that was amenable to X-ray diffraction (Scheme 5). As a result, we were able to assign the relative and absolute stereochemistry of [6,7,6,5]-core $\mathbf{2 5}$ and enyne product 26.

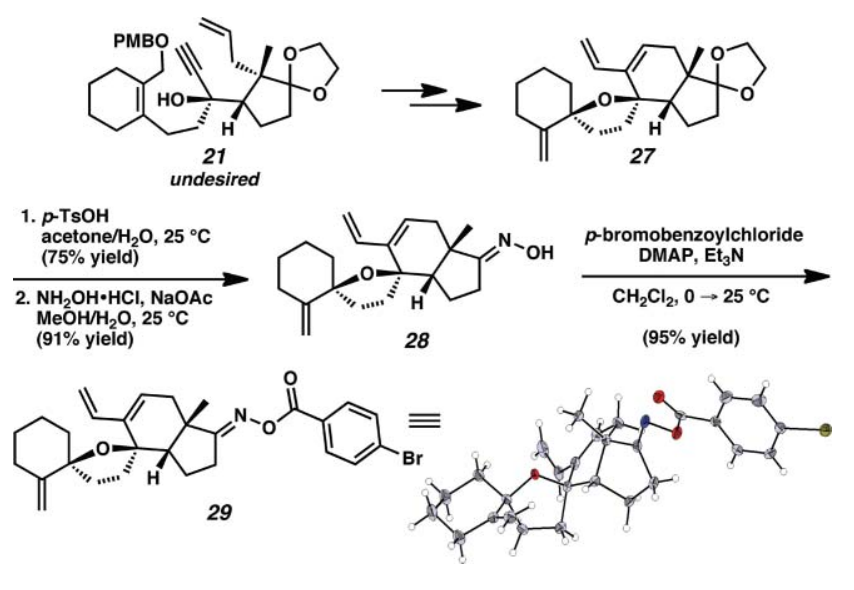

Scheme 5

Herein, we have established the enyne-ene metathesis as a rapid method for the construction of the carbocylic core of cortistatin A. We have also reported an unusual reaction in which an attempted $\mathrm{S}_{\mathrm{N}} 2$ displacement of a secondary mesylate on our five-membered D-ring piece gave product with retention of stereochemistry. Further studies directed toward the synthesis of cortistatin A and related analogs are underway and will be reported in due course.

\section{Acknowledgements}

C. B. thanks the Schweizerischer Nationalfonds (SNF) for a fellowship. This publication is based on work supported by Award No. KUS-11-006-02, made by King Abdullah University of Science and Technology (KAUST). Additionally, the authors thank Abbott, Amgen, Boehringer-Ingelheim, Bristol-Myers Squibb, Merck, Sigma-Aldrich and Caltech for generous funding. $\mathrm{Mr}$ Lawrence Henling and Dr Michael Day are gratefully acknowledged for X-ray crystallographic structural determination. The 
Bruker KAPPA APEXII X-ray diffractometer was purchased via an NSF CRIF:MU award to the California Institute of Technology, CHE-0639094. Dr David VanderVelde and Dr Scott Ross are acknowledged for NMR assistance. Dr Scott Virgil is acknowledged for helpful discussions.

\section{References}

1 (a) N. Ferrara and R. S. Kerbel, Nature, 2005, 438, 967-974; (b) J. Folkman, Nat. Rev. Drug Discovery, 2007, 6, 273-286, and references therein.

2 (a) S. Aoki, Y. Watanabe, D. Tanabe, A. Setiawan, M. Arai and M. Kobayashi, Tetrahedron Lett., 2007, 48, 4485-4488; (b) Y. Watanabe, S. Aoki, D. Tanabe, A. Setiawan and M. Kobayashi, Tetrahedron, 2007, 63, 4074-4079; (c) S. Aoki, Y. Watanabe, D. Tanabe, M. Arai, H. Suna, K. Miyamoto, H. Tsujibo, K. Tsujikawa, H. Yamamoto and M. Kobayashi, Bioorg. Med. Chem., 2007, 15, 6758-6762; (d) S. Aoki, Y. Watanabe, M. Sanagawa, A. Setiawan, N. Kotoku and M. Kobayashi, J. Am. Chem. Soc., 2006, 128, 3148-3149.

3 (a) R. A. Shenvi, C. A. Guerrero, J. Shi, C.-C. Li and P. S. Baran, J. Am. Chem. Soc., 2008, 130, 7241-7243; (b) K. C. Nicolaou, Y.-P. Sun, X.-S. Peng, D. Polet and D. Y.-K. Chen, Angew. Chem., Int. Ed., 2008, 47, 7310-7313; (c) H. M. Lee, C. Nieto-Oberhuber and M. D. Shair, J. Am. Chem. Soc., 2008, 130, 16864-16866; (d) K. C. Nicolaou, X.-S. Peng, Y.-P. Sun, D. Polet, B. Zou, C. S. Lim and D. Y.-K. Chen, J. Am. Chem. Soc., 2009, 131, 10587-10597; (e) E. M. Simmons,
A. R. Hardin-Narayan, X. Guo and R. Sarpong, Tetrahedron, 2010, 66, DOI: $10.1016 /$ j.tet.2010.01.030.

4 (a) J. Shi, H. Shigehisa, C. A. Guerrero, R. A. Shenvi, C.-C. Li and P. S. Baran, Angew. Chem. Int. Ed., 2009, 48, 4328-4331; (b) L. Liu, Y. Gao, C. Che, N. Wu, D. Z. Wang, C.-C. Li and Z. Yang, Chem. Commun., 2009, 662-664; (c) J. L. Frie, C. S. Jeffrey and E. J. Sorensen, Org. Lett., 2009, 11, 5394-5397; (d) P. Magnus and R. Littich, Org. Lett., 2009, 11, 3938-3941; (e) E. M. Simmons, A. R. Hardin, X. Guo and R. Sarpong, Angew. Chem., Int. Ed., 2008, 47, 6650-6653; (f) S. Yamashita, K. Iso and M. Hirama, Org. Lett., 2008, 10, 3413-3415; $(g)$ D. T. Craft and B. W. Gung, Tetrahedron Lett., 2008, 49, 5931-5934; (h) M. Dai and S. J. Danishefsky, Tetrahedron Lett., 2008, 49, 6610-6612; (i) L. Kürti, B. Czakó and E. J. Corey, Org. Lett., 2008, 10, 5247-5250.

5 (a) S.-H. Kim, N. Bowden and R. H. Grubbs, J. Am. Chem. Soc., 1994 116, 10801-10802; (b) S.-H. Kim, W. J. Zuercher, N. B. Bowden and R. H. Grubbs, J. Org. Chem., 1996, 61, 1073-1081; (c) T.-L. Choi and R. H. Grubbs, Chem. Commun., 2001, 2648-2649.

6 (a) D. W. Brooks, H. Mazdiyasni and P. G. Grothaus, J. Org. Chem., 1987, 52, 3223-3232.

7 (a) T. Rajamannar and K. K. Balasubramanian, Tetrahedron Lett., 1988, 29, 5789-5792; (b) S. P. Chavan, S. P. Chavan, H. R. Sonawane, U. R. Kalkote, S. G. Sudrik, R. G. Gonnade and M. M. Bhadbhade, Eur. J. Org. Chem., 2007, 3277-3280.

8 The enantiomeric excess of the benzoate derivative of alcohol 7 was determined by chiral HPLC to be $>99 \%$ ee. See the ESI for details $\dagger$.

9 See the ESI for detailst.

10 Determined by ${ }^{1} \mathrm{H}$ NMR. See the ESI for details

11 The percentage probability chosen for the ellipsoids is $50 \%$. 